\title{
Successful Treatment of Life-Threatening Metabolic Alkalosis Due to Pyloric Stenosis: A Rare Case
}

\author{
Siva Parcha ${ }^{\mathrm{a}, \mathrm{d}}$, Purnima Tripathy ${ }^{\mathrm{b}}$, Nikolay Azarov ${ }^{\mathrm{a}}$, Elaine De Prang ${ }^{\mathrm{c}}$, Yasir Ahmed ${ }^{\mathrm{a}}$
}

\begin{abstract}
Alkalemia is defined as blood $\mathrm{pH}>7.40$ and if severe alkalemia $\mathrm{pH}>7.60$. Metabolic alkalosis is one of the common in-hospital acid-base disorders. Gastric outlet obstruction secondary to pyloric stenosis has been reported most frequent causes of severe metabolic alkalosis resulting from volume and hydrogen ion loss. Mortality is directly related to the severity of the acid base disturbances. As serum $\mathrm{pH}$ exceeds 7.60 , the mortality also increases and can reach up to $80 \%$. The current case is of a 41 -year-old male with history of peptic ulcer disease presented with muscle cramps and confusion, and found to have severe metabolic alkalosis with an arterial $\mathrm{pH}$ of $7.91 \mathrm{~mm} \mathrm{Hg}$. He had superimposed acute kidney injury and severe hypokalemia which was successfully treated with aggressive volume repletion, hydrochloric acid infusion and surgery for pyloric stenosis. This is the severe reported life compatible level of metabolic alkalosis (pH: 7.91) to best our knowledge.
\end{abstract}

Keywords: Metabolic alkalosis; Acid-base disorders; Peptic ulcer disease; Acute pyloric stenosis

\section{Introduction}

Metabolic alkalosis is one of the common acid-base disorders seen in hospital especially in intensive care units. Severe metabolic alkalemia is a rare but fatal condition, which is defined as $\mathrm{pH}>7.60$, and usually requires serum $\mathrm{HCO}_{3}$ more than $40 \mathrm{mmol} / \mathrm{L}$. According to investigators, viable blood $\mathrm{pH}$ range is $6.80-7.80$. It could be a life-threatening condition if prompt diagnosis and timely management is not

\footnotetext{
Manuscript accepted for publication December 9, 2013

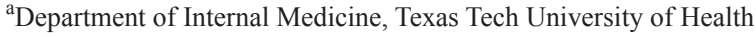
Science Center, Odessa, Texas, USA

${ }^{\mathrm{b}}$ Department of Internal Medicine, Cleveland Clinic, Ohio, USA

${ }^{\mathrm{c}}$ Medical Center Hospital, Odessa, Texas, USA

${ }^{\mathrm{d}}$ Corresponding author: Siva Parcha, Department of Internal Medicine,

Texas Tech University Health Science Center Odessa, Texas, USA.

Email: sivaprasadparcha@gmail.com
}

doi: http://dx.doi.org/10.14740/jmc1623w provided. Here we present a case of severe metabolic alkalosis secondary to acute pyloric stenosis, probably highest ever reported life compatible level that was successfully treated with rapid correction of alkalemia with intravenous fluids and hydrochloric acid.

We see this range of severe metabolic alkalosis seldom and hence managing such critical cases is a challenge to the physicians.

\section{Case Report}

A 41 years old male with history of peptic ulcer disease (PUD) presented with progressive dizziness associated with two episodes of syncope, paraesthesisas and confusion over a period of 3 days. Symptoms were preceded by severe nausea and intractable vomiting for 3 months. Patient endorsed $10-15 \mathrm{lb}$ weight loss during this period. He was diagnosed with PUD 6 months ago, but it was non-compliant with prescribed proton pump inhibitor (PPI).

Examination revealed extremely dehydrated, disoriented, thin frail man in moderate distress with heart rate: 94/ min, blood pressure: $127 / 81 \mathrm{~mm} \mathrm{Hg}$, respiratory rate: $24 / \mathrm{min}$ and temperature: $98^{\circ} \mathrm{F}$. Abdominal examination revealed hyperactive bowel sounds with mild distension and rest of systemic examinations was unremarkable.

Labs on admission suggested severe metabolic alkalosis with $\mathrm{pH}$ of $7.91 \mathrm{~mm} \mathrm{Hg}, \mathrm{HCO}_{3}^{-}: 62.8 \mathrm{mmol} / \mathrm{L}, \mathrm{pCO}_{2}: 31.2$ $\mathrm{mm} \mathrm{Hg}$.

Electrocardiogram showed normal sinus rhythm, ventricular rate of $83 / \mathrm{min}$ and significantly prolonged corrected QT $\left(\mathrm{QT}_{\mathrm{c}}\right)$ interval of $650 \mathrm{~ms}$. Urine electrolytes: random urine sodium $66 \mathrm{mmol} / \mathrm{L}$, random urine chloride $<20$ $\mathrm{mmol} / \mathrm{L}$. Given extreme dehydration and severe alkalosis he was admitted to ICU.

Patient received $12 \mathrm{~L}$ normal saline, potassium replacement, $500 \mathrm{mg}$ acetazolamide followed by $8.3 \mathrm{~mL}$ of $37 \%$ hydrochloric acid diluted in $1 \mathrm{~L}$ of normal saline given over 4 $\mathrm{h}$ via central venous line. We attempted rapid correction with hydrochloric acid infusion in view of severity of condition and patient recovered without any complication. Alkalemia was resolved in $8 \mathrm{~h}$ (Table 1). Computed tomography (CT) 
Table 1. Trends of the Arterial Blood Gases

\begin{tabular}{|c|c|c|c|c|c|}
\hline Arterial blood gas & Normal range & $\begin{array}{l}\text { Hospital day } 0 \\
0 \mathrm{~h}\end{array}$ & $\begin{array}{l}\text { Hospital day } 0 \\
8 \mathrm{~h}\end{array}$ & $\begin{array}{l}\text { Hospital day } 1 \\
12 \mathrm{~h}\end{array}$ & $\begin{array}{l}\text { Hospital day } 2 \\
36 \mathrm{~h}\end{array}$ \\
\hline $\mathrm{pH}(\mathrm{mm} \mathrm{Hg})^{1}$ & $7.35-7.45$ & 7.91 & 7.36 & 7.34 & 7.41 \\
\hline $\mathrm{pCO}_{2}(\mathrm{~mm} \mathrm{Hg})^{2}$ & $35-45$ & 31 & 39 & 37 & 25 \\
\hline $\mathrm{pO}_{2}(\mathrm{~mm} \mathrm{Hg})^{3}$ & $80-100$ & 60 & 59 & 89 & 105 \\
\hline $\mathrm{HCO}_{3}(\mathrm{mmol} / \mathrm{L})^{4,5}$ & $18-23$ & 63 & 22 & 20 & 16 \\
\hline
\end{tabular}

${ }^{1}$ millimeter of mercury; ${ }^{2}$ Carbon dioxide pressure; ${ }^{3}$ Oxygen pressure; ${ }^{4}$ bicarbonate; ${ }^{5}$ millimole per liter.

of abdomen following stabilization revealed marked gastric distention with sub mucosal edema likely causing acute pyloric stenosis. Patient underwent endoscopic evaluation which confirmed severe pyloric stenosis. He subsequently underwent vagotomy, antrectomy and placement of jejunal feeding tube. Tube feedings was initiated and he had a complete recovery in acid-base balance, electrolytes (Table 2) and $\mathrm{QT}_{\mathrm{c}}$ on the EKG by day 2. At 4 weeks follow-up, he was symptom free and was successfully transitioned to oral nutrition after discontinuation of jejunal tube feeds.

\section{Discussion}

Primary metabolic alkalosis is characterized as an acid-base disturbance associated with an elevated serum bicarbonate level $\left(\mathrm{HCO}_{3}\right)$ and accompanied by an elevation in extracellu$\operatorname{lar} \mathrm{pH}>7.40 \mathrm{~mm} \mathrm{Hg}$. Significant alkalosis is usually associated with alveolar hypoventilation as a compensatory mechanism to increase $\mathrm{pCO}_{2}$. This compensatory changes is fairly linear and is predicted by the equation $\mathrm{PaCO}_{2}=0.7\left(\mathrm{HCO}_{3}\right)$ +20 . Severe alkalemia is defined as $\mathrm{pH}>7.60 \mathrm{~mm} \mathrm{Hg}$ [1]. Hospitalized patients are particularly at risk for metabolic acidosis due to vomiting, frequent use of naso-gastric tube, and so on [2]. Mortality from alkalosis is close to $50 \%$ at $\mathrm{pH}$ greater than 7.60 and reached $80 \%$ when $\mathrm{pH}$ is more than $7.65 \mathrm{~mm} \mathrm{Hg}$, hence, prompt therapy is prudent.

Metabolic alkalosis with pH 7.87 as highest ever documented previously in a case report [3], but here we are presenting a patient with severe metabolic alkalosis with $\mathrm{pH}$

Table 2. Trends of the Electrolyte

\begin{tabular}{|c|c|c|c|c|c|}
\hline Electrolytes & Normal range & $\begin{array}{l}\text { Day } 0 \\
2 \mathrm{~h}\end{array}$ & $\begin{array}{l}\text { Day } 0 \\
8 \mathrm{~h}\end{array}$ & $\begin{array}{l}\text { Day } 1 \\
12 \mathrm{~h}\end{array}$ & $\begin{array}{l}\text { Day } 1 \\
16 \mathrm{~h}\end{array}$ \\
\hline Sodium $\left(\mathrm{mmol} / \mathrm{L}^{1}\right)$ & $132-144$ & 128 & 133 & 130 & 138 \\
\hline Potassium (mmol/L) & $3.4-4.9$ & 1.9 & 2.9 & 3.4 & 3.7 \\
\hline Chloride (mmol/L) & $101-112$ & 55 & 102 & 103 & 109 \\
\hline Total $\mathrm{CO}_{2}\left(\mathrm{mEq} / \mathrm{L}^{2}\right)$ & $20-29$ & 48 & 25 & 21 & 21 \\
\hline $\begin{array}{l}\text { Blood urea nitrogen }(\mathrm{mg} / \\
\left.\mathrm{dL}^{3}\right)\end{array}$ & $7-20.1$ & 63 & 37 & 36 & 31 \\
\hline Creatinine (mg/dL) & $0.6-1.2$ & 2.5 & 1.3 & 1.2 & 1 \\
\hline Calcium (mg/dL) & $8.7-10.3$ & 11.2 & 5.6 & 5.9 & 6.5 \\
\hline
\end{tabular}

Times shown are 12-h clock, ${ }^{1}$ millimoles per liter; ${ }^{2}$ milli-equivalents per liter; ${ }^{3}$ milligram per deciliter. 
7.91 which is probably highest ever reported to the best of our knowledge.

Metabolic alkalosis is classified as either saline responsive or saline non-responsive. Most common causes of saline responsive metabolic alkalosis are extracellular volume depletion, high doses of antacids, gastrointestinal fluid losses, diuretics, and so on. Mineralocorticoid excess is the most common cause of a saline nonresponsive state. These both can be easily distinguished by performing a spot urinary chloride level which is usually $<10 \mathrm{mEq} / \mathrm{L}$ in saline responsive and $>20 \mathrm{mEq} / \mathrm{L}$ in saline non-responsive metabolic alkalosis [4]. In healthy patients, loss of gastric secretions usually does not cause metabolic alkalosis until unless there is concomitant volume depletion and renal dysfunction [5]. Gastric outlet obstruction secondary to pyloric stenosis is reported as a common cause of severe metabolic alkalosis especially in children, but very rare in adults.

Clinical manifestations of metabolic alkalosis include apathy, confusion, cardiac arrhythmias, neuromuscular irritability, seizures and compensatory hypoventilation.

Treatment should focus on identifying the source, aggressive volume replacement and electrolyte correction and rescue therapy with acetazolamide. In refractory cases intravenous hydrochloric acid infusion via a large central vein can be given [1]. Hemodialysis with a high-chloride and low acetate dialysate has been reported but data is very limited in adult patient and only few anecdotal cases reported use of in pediatric population [6].

Our patient had neuromuscular manifestations including apathy, confusion and severe muscle cramps. Urine chloride was $<20 \mathrm{mEq} / \mathrm{L}$ favoring saline responsive metabolic alkalosis from intractable vomiting secondary to acute pyloric stenosis. His alkalemia was resolved with aggressive hydration, acetazolamide $500 \mathrm{mg}$ intravenously and $860 \mathrm{mEq}$ hydrochloric acid infusion through central vein over $6 \mathrm{~h}$. Later he underwent pyloric canal excision and dilatation without any complication.

Inadequately treated or advanced peptic ulcer diseases in adult's poses a risk of pyloric stenosis which can present with life-threatening metabolic. Timely intervention can prevent progression to morbid severe metabolic alkalosis and reduce overall mortality [7]. Even though it is recommended that in chronic metabolic alkalosis $\mathrm{pH}$ should be corrected very slowly, in exceptional critical cases like ours rapid correction of $\mathrm{pH}$ can be attempted in view of high mortality. Further studies should be done to confirm this.

\section{Disclosure}

All authors declare there is no conflict of interest and no financial disclosures related to this case.

\section{References}

1. Korkmaz A, Yildirim E, Aras N, Ercan F. Hydrochloric acid for treating metabolic alkalosis. Jpn J Surg. 1989;19(5):519-523.

2. Palmer BF, Alpern RJ. Metabolic alkalosis. J Am Soc Nephrol. 1997;8(9):1462-1469.

3. Tugrul S, Telci L, Yildirim A, Yanar H, Cakar N. Case report of severe metabolic alkalosis: life-compatible new level. J Trauma. 2010;68(3):E61-63.

4. Sherman RA, Eisinger RP. The use (and misuse) of urinary sodium and chloride measurements. JAMA. 1982;247(22):3121-3124.

5. Tannen RL, Bleich HL, Schwartz WB. The renal response to acid loads in metabolic alkalosis; an assessment of the mechanisms regulating acid excretion. J Clin Invest. 1966;45(4):562-572.

6. Banieghbal B. Rapid correction of metabolic alkalosis in hypertrophic pyloric stenosis with intravenous cimetidine: preliminary results. Pediatr Surg Int. 2009;25(3):269-271.

7. Anderson LE, Henrich WL. Alkalemia-associated morbidity and mortality in medical and surgical patients. South Med J. 1987;80(6):729-733. 